\title{
TO STUDY THE USEFULNESS OF CBNAAT (CARTRIDGE BASED NUCLEAR ACID AMPLIFICATION TEST) IN BAL (BRONCHOALVEOLAR LAVAGE) SAMPLES IN THE DIAGNOSIS OF SMEAR-NEGATIVE/NON SPUTUM PRODUCING PATIENTS WITH SUSPECTED TUBERCULOSIS
}

\author{
Sanjay Avashia1, Satyadeo Choubey², Satyendra Mishra ${ }^{3}$, Atul Kharate ${ }^{4}$ \\ ${ }^{1} H O D$ \& Associate Professor, Department of Pulmonary Medicine, MGM Medical College, Indore. \\ ${ }^{2}$ Assistant Professor, Department of Pulmonary Medicine, MGM Medical College, Indore. \\ 3Junior Resident, Department of Pulmonary Medicine, MGM Medical College, Indore. \\ ${ }^{4}$ State TB Officer, Ministry of Health \& Family Welfare, Government of Madhya Pradesh.
}

\begin{tabular}{l} 
ABSTRACT \\
\hline BACKGROUND \\
Sputum smear negative pulmonary tuberculosis remains a significant burden with a definite role in disease transmission too. \\
They sometimes pose a diagnostic challenge to the treating physician. CBNAAT, a newly endorsed WHO technique, which not only \\
detects the tubercle bacilli but also tells about the resistance to rifampicin, may have a role in sputum smear negative patients if \\
bronchoalveolar lavage fluid is made available.
\end{tabular}

\section{MATERIAL AND METHODS}

Clinico-radiologically suspected patients of pulmonary tuberculosis who were either sputum negative or not bringing out adequate sputum sample were included in the study. Included patients who do not have contraindications to bronchoscopy were subjected to the procedure and lavage fluid was obtained. Smear and CBNAAT examination of the fluid were done. The data recorded was then analysed statistically.

\section{RESULT}

In our study out of total 72 cases, $56.9 \%$ were male while $43.1 \%$ population were of female. Majority of patients belonged to Urban (86.1\%) as compared to rural area (13.9\%). The most common lesions detected by chest imaging were consolidation (33.3\%) followed by fibrocavitary (11.1\%). Otherwise not specified opacities constituted about $27.8 \%$. Out of 37 bacteriologically confirmed cases 3 were positive in BAL smear microscopy, while 34 were positive by CBNAAT. Out of 34 CBNAAT positive samples, 3 were resistant to Rifampicin.

\section{CONCLUSION}

CBNAAT done on broncho-alveolar lavage fluid obtained via bronchoscopy can be an important adjunct to bacteriological confirmation of suspected cases who were otherwise sputum negative or not bringing adequate sputum sample. Moreover resistance to rifampicin can be detected prior to the treatment.

\section{KEYWORDS}

CBNAAT, Tuberculosis, BAL, Gene Xpert.

HOW TO CITE THIS ARTICLE: Avashia S, Choubey S, Mishra S, et al. To study the usefulness of CBNAAT (cartridge based nuclear acid amplification test) in BAL (bronchoalveolar lavage) samples in the diagnosis of smear-negative/non-sputum producing patients with suspected tuberculosis. J Evolution Med Dent Sci 2016;5(1):55-59, DOI: 10.14260/jemds/2016/13

\section{INTRODUCTION}

Tuberculosis is one of the oldest diseases known to human being, still causing a large number of mortality and morbidity throughout the developing world. Many patients presenting with active Pulmonary Tuberculosis (PTB) may, however, exhibit negative sputum Acid-Fast Bacilli (AFB) smears. In low Tuberculosis (TB) burden country like France $73 \%$ of all TB cases were pulmonary tuberculosis. Among them about 50\% were sputum smear negative. ${ }^{1}$ In our institute in 2012 out of 519 of PTB case 167 were sputum negative, 130 cases were sputum negative out of 399 PTB cases in 2013 whereas in 2014 out of 439 of all PTB cases 227 were diagnosed as sputum negative PTB.

Financial or Other, Competing Interest: None.

Submission 13-12-2015, Peer Review 14-12-2015,

Acceptance 29-12-2015, Published 02-01-2016.

Corresponding Author:

Dr. Sanjay Avashia,

5/14, Y. N. Road, Rani Sati Colony,

Indore-452003.

E-mail: sanjayavashia66@yahoo.com

DOI:10.14260/jemds/2016/13
Thus about more than half of the cases were sputum negative in the last three years.

A substantive number of pulmonary tuberculosis patients remain undiagnosed by conventional sputum microscopy. These cases also play an important role in the disease transmission. Moreover on the basis of Chest radiography only as the diagnostic tool, many patients are wrongly started on Anti-Tubercular Treatment (ATT). In the above two situations, Cartridge Based Nuclear Acid Amplification Test (CBNAAT) of BAL (Bronchoalveolar Lavage) looks convincing as a good diagnostic method for the purpose of diagnosing or ruling out pulmonary tuberculosis. By detecting active pulmonary TB early, an appropriate treatment can be initiated, lung damage can be prevented and disease transmission can be pre-emptively blocked. Fiberoptic bronchoscopy is considered a good option for these cases that pose a diagnostic challenge. ${ }^{2}$ although smear microscopy is still exhibiting low sensitivity on fiberoptic bronchoscopy samples with 5-35\% on Bronchial Aspirates (BA) and 10-30\% on Bronchoalveolar Lavages (BAL). ${ }^{3.4}$ 
Furthermore, while mycobacterial culture remains the gold standard for laboratory diagnosis of TB, it requires 2-6 weeks to confirm a diagnosis and there are fewer accredited labs. This results in delay in initiating appropriate treatment while waiting for the confirmation, except for the cases where there is strong clinical suspicion to initiate a presumptive antiTB therapy. Several Polymerase Chain Reaction - (PCR) based molecular methods have recently been developed for early TB diagnosis and rapid detection of drug resistance from clinical specimens. ${ }^{5,6}$ The CBNAAT (Cartridge Based Nuclear Acid Amplification Test) is one of these methods and consists of a hemi-nested real-time PCR test that simultaneously identifies mycobacterium tuberculosis and detects rifampicin resistance as a surrogate of Multidrug Resistance (MDR), directly from clinical specimens. Since December 2010, WHO has recommended the CBNAAT as a bona fide test due to its highquality performance as compared to microscopy, especially in cases of smear-negative cases. ${ }^{7}$

\section{MATERIAL AND METHODS}

This study was to evaluate the diagnostic value of the CBNAAT on BAL samples obtained through fiber-optic bronchoscopy for an early diagnosis of pulmonary TB in patients with either negative sputum smear for AFB or who could not produce an expectorated sputum sample.

\section{Inclusion Criteria}

Patients with clinical suspicion of PTB based on symptoms (e.g., cough more than two weeks, hemoptysis, fever, asthenia, loss of weight and night sweats) or radiological features (e.g., nodule, consolidation, cavation and other opacities) who either have a negative sputum AFB smear microscopy or were unable to produce sputum were included in the study.

\section{Exclusion Criteria}

Sputum positive cases, isolated extra-pulmonary tuberculosis, HIV positive patients and patients not fit for bronchoscopy procedure, e.g. those having refractive hypoxemia, bleeding disorders, cardiovascular instability, status asthmaticus and marked hypercapnia were excluded from the study.

\section{Selection of Cases}

Patients having clinical or radiological suspicion of pulmonary tuberculosis who met both inclusion and exclusion criteria were then planned for a diagnostic fiberoptic bronchoscopy procedure at MY Hospital, Indore. In this group, we included those cases whose symptoms did not resolved completely after appropriate antibiotic treatment.

\section{Bronchoscopic Procedure}

Pre-operative procedure included overnight fasting, lignocaine sensitivity test, Inj. ondansetron administration, intravenous drip, intramuscular atropine administration, oropharyngeal local $2 \%$ lignocaine spray, intra-nasal application of $5 \%$ lignocaine jelly.
After taking informed consent, under all aseptic precautions bronchoscopy was performed via transnasal route using a flexible fiberoptic bronchoscope by a trained chest specialist to collect BAL specimens. Lignocaine $2 \%$ was used as local anaesthesia to anaesthetize vocal cords and bronchial tree. The lung section samples were chosen based on chest X-ray or CT-scan abnormalities. BAL samples were obtained after instillation of $100-200 \mathrm{~mL}$ isotonic saline in serial aliquots using $10 \mathrm{ml}$ disposable syringe with bronchoscope wedged in a segmental or sub-segmental bronchus and then aspirated. BAL samples thus obtained were then analyzed by microscopic examination and by CBNAAT.

\section{Microscopic Examination}

For the smear examination, fixed preparations were stained with ZN staining and visualized under an oil field microscope (At 400x magnification). Each slide was observed for 5-10min, corresponding to 100 fields examined. Samples which were negative for AFB microscopy underwent CBNAAT.

\section{CBNAAT}

For the CBNAAT, a $500 \mu \mathrm{L}$ BAL sample was poured into a single-use disposable cartridge that is placed into the Xpert Dx module with the results produced in less than 2 hours. Each PCR run comprised an internal control for sample processing (DNA extraction) and PCR validity (Presence of inhibitors) with positive and negative controls tested everyday. The system automatically interpreted all results from measured fluorescent signals, with embedded calculation algorithms, into the following categories: invalid, if PCR inhibitors are detected with amplification failure; negative or positive. If positive, the strain was categorized as susceptible or resistant to rifampicin.

\section{RESULTS}

In our study among all 72 sputum negative suspected PTB patients underwent bronchoscopy and BAL samples were collected. All the 72 BAL samples underwent smear microscopy and 3 smear samples came positive of AFB, remaining 69 BAL samples which were negative for smear microscopy underwent CBNAAT. Among these 69 BAL samples, mycobacterium tuberculosis was detected in $34 \mathrm{BAL}$ samples. Among these 34 BAL samples, 31 BAL samples were sensitive to rifampicin while 3 were resistance. Rest 35 BAL CBNAAT negative patients were kept in follow-up on antibiotic therapy, on the basis of BAL culture and sensitivity report and majority of them were improved. 


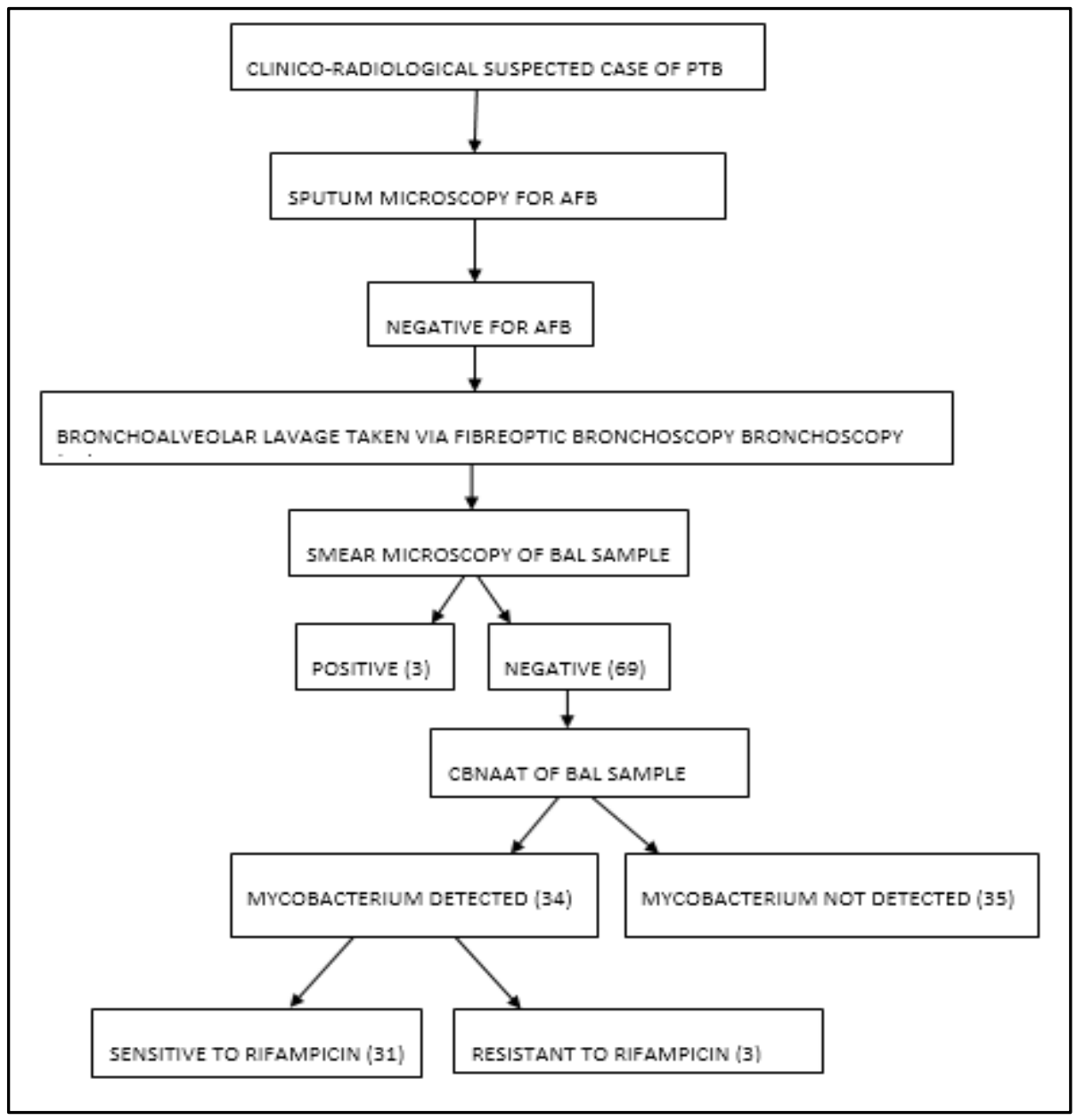

\begin{tabular}{|c|c|c|}
\hline Demographic Characters & Frequency & Percentage \\
\hline Male & 41 & 56.9 \\
\hline Female & 31 & 43.1 \\
\hline Urban & 62 & 86.1 \\
\hline Rural & 10 & 13.9 \\
\hline Table 1: Demographic Characteristics \\
\hline
\end{tabular}

\begin{tabular}{|c|c|c|}
\hline Results & Frequency & Percentage \\
\hline Total cases & 72 & 100 \\
\hline $\begin{array}{c}\text { Bacteriologically confirmed } \\
\text { PTB }\end{array}$ & 37 & 51.4 \\
\hline BAL Smear positives & 03 & 4.2 \\
\hline $\begin{array}{c}\text { BAL Smear negative, but } \\
\text { CBNAAT positive }\end{array}$ & 34 & 47.2 \\
\hline Rifampicin resistant & 03 & 4.2 \\
\hline Rifampicin sensitive & 31 & 43.1 \\
\hline \multicolumn{2}{|c|}{ Table 4: Results of Tests } \\
\hline
\end{tabular}

\begin{tabular}{|c|c|c|}
\hline Symptoms & Frequency & Percentage \\
\hline Cough & 52 & 72.2 \\
\hline Hemoptysis & 7 & 9.7 \\
\hline Loss of appetite & 43 & 59.7 \\
\hline Weight loss & 36 & 50 \\
\hline Fever & 50 & 69.4 \\
\hline Night sweats & 14 & 19.4 \\
\hline \multicolumn{2}{|c|}{ Table 2: Presenting Symptoms } \\
\hline
\end{tabular}

\begin{tabular}{|c|c|c|}
\hline Radiological Characters & Frequency & Percentage \\
\hline Consolidation & 24 & 33.3 \\
\hline Fibrocavitary lesions & 08 & 11.1 \\
\hline Nodules & 02 & 2.8 \\
\hline Mass & 02 & 2.8 \\
\hline Interstitial shadows & 02 & 2.8 \\
\hline Thick wall cavity & 02 & 2.8 \\
\hline Bronchiectasis changes & 05 & 6.7 \\
\hline Other opacities & 20 & 27.8 \\
\hline Normal & 07 & 9.7 \\
\hline \multicolumn{3}{|c|}{ Table 3: Radiological Features } \\
\hline
\end{tabular}

\begin{tabular}{|c|c|c|c|c|c|}
\hline $\begin{array}{c}\text { Total } \\
\text { clinic- } \\
\text { radiologi } \\
\text { cal PTB } \\
\text { suspects } \\
(\mathrm{n}= \\
\mathrm{a}+\mathrm{b}+\mathrm{c})\end{array}$ & $\begin{array}{l}\text { Sputu } \\
\text { m } \\
\text { Smear } \\
\text { positi } \\
\text { ve }\end{array}$ & $\begin{array}{l}\text { BAL } \\
\text { smear } \\
\text { positi } \\
\text { ve (a) }\end{array}$ & $\begin{array}{l}\text { CBNA } \\
\text { AT } \\
\text { positiv } \\
\text { e (b) }\end{array}$ & $\begin{array}{c}\text { Total } \\
\text { Bacteriologi } \\
\text { cal } \\
\text { confirmed } \\
\text { cases }(a+b)\end{array}$ & $\begin{array}{l}\text { Neithe } \\
\text { r BAL } \\
\text { smear } \\
\text { nor } \\
\text { CBNA } \\
\text { AT } \\
\text { positiv } \\
\text { e (c) }\end{array}$ \\
\hline 72 & 0 & 3 & 34 & 37 & 35 \\
\hline
\end{tabular}

\section{Discussion}

Sputum negative pulmonary tuberculosis constitutes about $50 \%$ of all new cases of pulmonary tuberculosis. Although the relative transmission rate of smear negative tuberculosis is lower than that of smear positive cases, it is still responsible for $17 \%$ of tuberculosis transmission. ${ }^{8}$

Conventional laboratory techniques like direct microscopy are less sensitive and going for culture is a time consuming process for the diagnosis of tuberculosis. 
Therefore it is the need of time to develop new techniques for rapid identification of the Mycobacterium tuberculosis in pauci-bacillary samples. Recently, attention has been devoted to latest nucleic acid amplification diagnostic processes due to their speed and accuracy.

\begin{tabular}{|c|c|c|}
\hline Techniques & Advantages & Disadvantages \\
\hline $\begin{array}{l}\text { Ziehl-Neelsen } \\
\text { Microscopy }\end{array}$ & Cheap & $\begin{array}{c}\text { At least } 10,000 \\
\text { bacili per ml of } \\
\text { sputum is required } \\
\text { Low sensitivity in } \\
\text { paucibacillary } \\
\text { samples }\end{array}$ \\
\hline $\begin{array}{l}\text { Fluorescent } \\
\text { Microscopy }\end{array}$ & $\begin{array}{l}\text { - More samples can } \\
\text { be examined than } \\
\text { ZN microscopy } \\
\text { - Good for high load } \\
\text { settings (>25 smear } \\
\text { per day) } \\
\text { - Require less time } \\
\text { than ZN microscopy }\end{array}$ & $\begin{array}{l}\text { - Costly compared } \\
\text { to ZN Microscopy }\end{array}$ \\
\hline $\begin{array}{l}\text { Solid Culture } \\
\text { (LJ) }\end{array}$ & $\begin{array}{l}\text {-Sensitivity } 80-85 \% \\
\text { \& Specificity } 98 \% \\
\text { - Ideal for diagnosis } \\
\text { and follow-up } \\
\text {-Applicable for } \\
\text { MDR-TB \& XDR-TB }\end{array}$ & $\begin{array}{l}\text { - Growth takes 6-8 } \\
\text { weeks } \\
\text { - Lengthy time for } \\
\text { certification } \\
\text { - Required trained } \\
\text { manpower }\end{array}$ \\
\hline $\begin{array}{l}\text { Liquid } \\
\text { Culture } \\
\text { (MGIT) }\end{array}$ & $\begin{array}{l}\text { - More sensitive \& } \\
\text { can be positive even } \\
\text { when bacterial load } \\
\text { is low }(10-100 \\
\text { bacilli/ml) } \\
\text { - Rapid detection (4- } \\
21 \text { days) and DST } \\
\text { (15-28 days) } \\
\text {-Applicable for } \\
\text { diagnosis and } \\
\text { follow-up } \\
\text {-Applicable for } \\
\text { MDR-TB \& XDR-TB }\end{array}$ & $\begin{array}{l}\text {-BSL-III facility } \\
\text { essential } \\
\text {-Continuous } \\
\text { power supply } \\
\text {-Trained } \\
\text { Manpower } \\
\text {-Higher } \\
\text { contamination }\end{array}$ \\
\hline $\begin{array}{l}\text { Molecular } \\
\text { DST(LPA) }\end{array}$ & $\begin{array}{l}\text { •Rapid turnaround } \\
\text { time (TAT), within } \\
\text { 5days } \\
\text { •Highly sensitive } \\
\text { and specific ( } 99 \% \\
\text { RIF \&80\%INH) } \\
\text {-High Out-put } \\
\text { laboratory with GT- } \\
\text { BLOT ( } 40 \text { test per } \\
\text { day) }\end{array}$ & $\begin{array}{l}\cdot \text { Trained } \\
\text { manpower } \\
\text { •Only applicable } \\
\text { for smear positive } \\
\text { TB patients } \\
\text { - Labour Intensive } \\
\text {-Detects only for } \\
\text { first line Drug } \\
(\mathrm{H} \& \mathrm{R}) \\
\text {-Only for } \\
\text { diagnosis }\end{array}$ \\
\hline CBNAAT & $\begin{array}{l}\text {-Rapid turnaround } \\
\text { time within } 2 \text { hours } \\
\text {-require bio-safety } \\
\text { conditions similar } \\
\text { to the conventional } \\
\text { sputum smear } \\
\text { microscopy sample } \\
\text {-Minimal Training } \\
\text { for LT } \\
\text {-Inbuilt quality } \\
\text { control for process }\end{array}$ & $\begin{array}{l}\text {-Stable electricity } \\
\text { supply } \\
\text { - Require ambient } \\
\text { operating } \\
\text { temperatures max. } \\
\text { 30C } \\
\text { - Only detects } \\
\text { Rifampicin } \\
\text { resistance } \\
\text {-Annual } \\
\text { Calibration } \\
\text { - Only for } \\
\text { diagnosis }\end{array}$ \\
\hline \multicolumn{3}{|c|}{$\begin{array}{l}\text { Table 6. }{ }^{9} \text { : Comparison of various } \\
\text { method for PTB diagnosis }\end{array}$} \\
\hline
\end{tabular}

A 2013 Cochrane systematic review showed that this test is highly accurate. ${ }^{10}$ when compared to culture, Xpert has about $88 \%$ sensitivity and $98 \%$ specificity for pulmonary TB in adults. In smear-negative patients with TB, Xpert had a sensitivity of $67 \%$. For rapid detection of rifampicin resistance, the sensitivity is $94 \%$ and specificity is $98 \%$. As per Panayotis Ioannidis et al. ${ }^{11}$ positive and negative predictive values of GeneXpert MTB/RIF assay for the pulmonary are 93.5\% and $91.7 \%$ and for the extrapulmonary samples, they are $50 \%$ and $100 \%$, respectively. For microscopically negative specimens, the respective values are $79 \%$ and $95.6 \%$.

In our study out of total 72 cases, $56.9 \%$ were male while $43.1 \%$ population were of female. Majority of patients belonged to Urban $(86.1 \%)$ as compared to rural area $(13.9 \%)$. Most common symptom in our study was cough (72.2\%) followed by fever (69.4\%). In a similar study from France Le Palud et al. in 2014 found cough (51.9\%) as the main symptom followed by general symptoms (45.1\%). ${ }^{12}$ In majority of patients in our study more than two symptoms were present. The most common lesions detected by chest imaging were consolidation (33.3\%) and fibrocavitary diseases (11.1\%). Otherwise, not specified opacities constituted about $27.8 \%$. Chest imaging was normal in $9.7 \%$ cases, whereas in study by Le Palud et al. nodules (53.7) were the most common radiological finding followed by Pneumonia (27.1\%).12

Out of 72 clinico-radiologically suspected patients, only 3 were BAL smear positive while another 34 were further detected by CBNAAT giving a total bacteriological figure of 37 . Out of 34 CBNAAT positive samples, 3 were resistant to Rifampicin. Raquel Moure et al. in their research in 2012 concluded that out of 108 smear-negative extrapulmonary samples $58.3 \%$ were positive with the Xpert MTB/RIF assay (GX) for Mycobacterium tuberculosis. ${ }^{13}$ In a similar study by Vadwai in 2011, the sensitivity of the Xpert assay was $64 \%$ for smear-negative cases. ${ }^{14}$ Our results are little lower $(47.2 \%)$ than these two study as we had not performed CBNAAT on BAL smear AFB positive samples and our sample size was much less as compared to other studies.

Lee et al. recruited 132 patients in a single South-Korean centre and reported sensitivity and specificity values (relative to the culture) of $81.6 \%$ and $100.0 \%$ for the Xpert ${ }^{\circledR}$ MTB/RIF assay, compared to $13.2 \%$ and $98.8 \%$ respectively for smear microscopy. 15 Theron et al. In their study of 154 patients in a South-African single-centre study analysed the BAL samples in which sensitivity and specificity values compared to the culture were $92.6 \%$ and $96.0 \%$ for the Xpert $\AA$ MTB/RIF assay, and $57.7 \%$ and $99.3 \%$ for SM, respectively. ${ }^{16}$ Le Palud et al. concluded that as compared to culture, sensitivity and specificity values were $80.0 \%$ and $98.6 \%$ for the Xpert ${ }^{\circledR}$ MTB/RIF assay. ${ }^{12}$

\section{CONCLUSION}

In summary, our study confirmed the usefulness of the Xpert ${ }^{\circledR}$ MTB/RIF assay (CBNAAT), compared to Smear Microscopy, for the early diagnosis of suspected pulmonary TB requiring fibre-optic bronchoscopy, performed on per procedure samples. Gene Xpert MTB/RIF assay is efficient and reliable technique for the rapid smear negative cases. Its simplicity, sensitivity, speed and automation, make this technique a very attractive tool for diagnosis of Mycobacterium tuberculosis from smear negative cases of TB suspects. Meanwhile it has an added advantage of detection of multi-drug resistant cases. 


\section{REFERENCES}

1. Antoine D, Che D: Les cas de tuberculose déclarés en France en 2010. Bull Epidémiol Hebd 2012;24-25:285-287.

2. Mohan A, Sharma SK. Fiberoptic bronchoscopy in the diagnosis of sputum smear-negative pulmonary tuberculosis: current status. Indian J Chest Dis Allied Sci 2008;50:67-78.

3. Chawla R, Pant K, Jaggi OP, et al. Fiberoptic bronchoscopy in smear negative pulmonary tuberculosis. Eur Respir J 1988;1:804-6.

4. Chan HS, Sun AJ, Hoheisel GB. Bronchoscopic aspiration and bronchoalveolar lavage in the diagnosis of sputum smear-negative pulmonary tuberculosis.

Lung 1990;168:215-220.

5. Wong CF, Yew WW, Chan CY, Au LY, Cheung SW, Cheng AF. Rapid diagnosis of smear-negative pulmonary tuberculosis via fiberoptic bronchoscopy: utility of polymerase chain reaction in bronchial aspirates as an adjunct to transbronchial biopsies. Respir Med 1998;92:815-9.

6. Chen NH, Liu YC, Tsao TC, Wu TL, Hsieh MJ, Chuang ML, et al. Combined bronchoalveolar lavage and polymerase chain reaction in the diagnosis of pulmonary tuberculosis in smear-negative patients. Int J Tuberc Lung Dis 2002;6:350-5.

7. World Health Organization: WHO report 2010: global tuberculosis control. Geneva, Switzerland: WHO; 2010

8. Behr MA, Warren SA, Salamon H, Hopewell PC, Ponce de Leon A, Daley CL, et al. Transmission of mycobacterium tuberculosis from patients smear negative for acid-fast bacilli. Lancet 1999;353:444-9.

9. Stop TB Partnership and World Health Organization. New Laboratory Diagnostic Tools for TB Control. Geneva, World Health Organization, 2008.

10. Karen R Steingart, Hojoon Sohn, Ian Schiller, Lorie A

Kloda, Catharina C Boehme, Madhukar Pai, et al.

Cochrane Library 2013

http://doi.wiley.com/10.1002/14651858.CD009593.pu

b2.
11. Panayotis Ioannidis, Dimitrios Papaventsis, Simona Karabela, Stavroula Nikolaou, Marina Panagi, Ekaterini Raftopoulou, et al. Cepheid GeneXpert MTB/RIF assay for mycobacterium tuberculosis detection and rifampin resistance identification in patients with substantial clinical indications of tuberculosis and smear-negative microscopy results. Journal of Clinical Microbiology, Aug. 2011, p. 3068-3070 0095-1137/11/ doi:10.1128/JCM.00718-11.

12. Pierre Le Palud, Vincent Cattoir, Brigitte Malbruny, Romain Magnier, Karine Campbell, Youssef Oulkhouir1, et al. Retrospective observational study of diagnostic accuracy of the Xpert ${ }^{\circledR}$ MTB/RIF assay on fiberoptic bronchoscopy sampling for early diagnosis of smearnegative or sputum-scarce patients with suspected tuberculosis. BMC Pulmonary Medicine 2014;14:137

13. Moure R, Martín R, Alcaide F. Effectiveness of an integrated real-time PCR method for detection of the mycobacterium tuberculosis complex in smear-negative extrapulmonary samples in an area of low tuberculosis prevalence. 50(2), 2012, 513.

14. Vadwai V, Boehme C, Nabeta P, Shetty A, Alland D, Rodrigues C. Xpert MTB/RIF, a New Pillar in diagnosis of extrapulmonary tuberculosis? J Clin Microbiol 2011;49:2540-2545.

15. Lee HY, Seong MW, Park SS, Hwang SS, Lee J, Park YS, et al.: Diagnostic accuracy of Xpert MTB/RIF on bronchoscopy specimens in patients with suspected pulmonary tuberculosis. Int J Tuberc Lung Dis 2013;17:917-921.

16. Theron G, Peter J, Meldau R, Khalfey H, Gina P, Matinyena B, et al.: Accuracy and impact of Xpert MTB/RIF for the diagnosis of smear negative or sputum-scarce tuberculosis using bronchoalveolar lavage fluid. Thorax 2013;68:1043-1051. 